\title{
A new DEA-GAHP method for supplier selection problem
}

\author{
Behrooz Ahadian*, Abolfazl Gholipour Mehdi Abadi and Roshan Motamed Chaboki
}

Department of Industrial Engineering, Science and Research Branch, Islamic Azad University, Hormozgan, Iran

\begin{tabular}{l}
\hline A R T I C L E I N F O \\
\hline Article history: \\
Received April 20, 2012 \\
Accepted 21 July 2012 \\
Available online \\
July 22 2012 \\
\hline Keywords: \\
Data envelopment analysis (DEA) \\
Group analytical hierarchy \\
process (GAHP) \\
Supplier selection \\
Supply chain management \\
\end{tabular}

\section{A B S T R A C T}

Supplier selection is one of the most important decisions made in supply chain management. Supplier evaluation problem has been in the center of supply chain researcher's attention in these years. Managers regard some of these studies and methods inappropriate due to simple, weight scoring methods that generally are based on subjective opinions and judgments of decision maker units involved in the supplier evaluation process yielding imprecise and even unreliable results. This paper seeks to propose a methodology to integrate data envelopment analysis (DEA) and group analytical hierarchy process (GAHP) for evaluating and selecting the most efficient supplier. We develop a methodology, which consists of 6 steps, one by one has been introduced in lecture and finally applicability of proposed method is indicated by assessing 12 suppliers in a numerical example.

(C) 2012 Growing Science Ltd. All rights reserved.

\section{Introduction}

In a high competitive era of manufacturing, supply chain management success usually depends on selecting the most appropriate suppliers and vendors. The success of a supply chain is highly dependent on selection of good suppliers $(\mathrm{Ng}, 2008)$. Although globalization has prepared opportunities for many firms to use sources from around the world, but a simultaneous evaluation of supplier performance attributes such as quality, price/cost, delivery, safety etc. have to be implemented to ensure business competitiveness, success and sustainability. It has been stressed in the literature (Banker \& Khosla 1995, Leenders et al., 2006; Monczka et al., 2002; Heizer \& Render, 2006) on how important is to select proper supplier and its impact on the entire performance of the organization. Over the past decade, many techniques and approaches have been proposed by researchers and many mathematical methodologies have been developed to solve the supplier's decision-making problem, efficiently. By searching into literature review and relevant literature review papers such as Ho et al. (2009) we can find these methodologies. Mathematical programming such as linear programming by (Talluri \& Narasimhan, 2003-2005), and Ng (2008), Integer linear programming Talluri(2002) and Hong et al. (2005), Integer non-linear programming by Ghodsypour

* Corresponding author. Tel: +989188140168

E-mail addresses: behrooz.ahadian@yahoo.com (B. Ahadian) 
and O'Brien (2001), Goal programming (Karpak et al., 2001), Multi-objective programming (Narasimhan et al., 2006; Wadhwa \& Ravindran, 2007). Analytic hierarchy process (Chan \& Chan, 2004; Liu \& Hai, 2005; Hou \& Su, 2007), Analytic network process (Bayazit, 2006; Gencer \& Gürpinar, 2007) and Fuzzy set theory (Chen et al., 2006; Sarkar \& Mohapatra, 2006; Florez Lopez, 2007). But major researches proposed for supplier's evaluation and selection problem includes use of data envelopment analysis (DEA). DEA was first developed by Charnes et al. (1987) as a systematic analysis method based on the relative efficiency which promotes the concept of single-input and single-output efficiency to the evaluation of multiple-input and multiple output decision making (DMU) (Charnes et al., 1987). Nowadays DEA has attracted many researchers attention and the applicability and successful application of this method could be the reason of widespread utilization of DEA. Petroni (2000), Forker and Mendez (2001), Talluri and Baker (2002), Talluri and Narasimhan (2004), Garfamy (2006), Saen (2007a) are some of previous supplier selection researches based on DEA method.

This paper is organized as follows: section 2 deals with previous supplier selection lectures using various models. In section 3 the proposed DEA-GAHP model will be explained. Section 4 illustrates application of proposed method. Finally the lecture closes with a conclusion.

\section{Literature review}

Previously many methods have been used for the subject of supplier selection. Weber et al. (2000) used an integrated DEA and multi-objective programming in order to find the optimal amount of orders and evaluated the efficiency of the multi objective programming constraint effects on different suppliers. Forker and Mendez (2001) developed a DEA based model to find the best peer supplier by measuring the comparative efficiency with a single input and multi outputs. Narasimhan et al. (2001) aimed to propose a technique to evaluate alternative suppliers based on statistical indicators and Cross-Efficiencies by classifying suppliers into four categories using eleven evaluating factors. Talluri and Baker (2002) used a multi-phase approach for designing logistics distribution networks. In stage I potential suppliers, manufacturers and distributors were evaluated separately based on Game Theory, and Linear and Integer Programming methods using six evaluating factors, including two inputs and four outputs. Based on the scores obtained in stage I and optimal number of stakeholders in stage II, the optimal routing of material were identified by minimizing the total cost. Talluri and Narasimhan (2004) proposed a method to classify suppliers into various clusters using statistical and cross-efficiencies methods. Saydel (2005) used SMART approach (Simple MultiAttribute Rating Technique) and DEA to demonstrate the performance of 10 suppliers. To identify the optimal order quantity and determine the optimal number of suppliers Hong et al. (2005) developed an Integer linear programming and maximized revenue in overall supply chain. Seydel (2006) unlike previous models instead of considering both inputs and outputs did not focus on inputs. His proposed model in comparison with the SMART methodology required less involvement of decision makers and less data. Garfamy (2006) applied DEA to measure the overall performance of suppliers focusing on Total Cost of Ownership (TCO). A supplier providing the lowest costs per unit was regarded as the most efficient one. Ross et al. (2006) used DEA to evaluate the supplier performance focusing on buyer's perspective and attributes by implementing three sensitivity analyses on supplier's and buyer's preferences. Saen (2007a) developed an imprecise DEA evaluation for using in some criteria like supplier reputation, which could not be quantified, easily. His new method includes cardinal and ordinal data in a fuzzy set so that decision makers could rank suppliers based on SR. Ramanathan (2007) based on previous studies of Bhutta and Huq (2002) on suppliers performance evaluation using Total Cost of Ownership (TCO) suggested using both quantitative and qualitative information obtained from (TCO) and AHP as input and output in DEA model, respectively. Wu et al. (2007) presented an improved DEA model for supplier selection problem to deal with imprecise data in order to classify suppliers. It also has more potential for further 
discrimination of efficiently selection to differentiate efficient suppliers from others. Saen (2007b) proposed an innovative approach, which combines AHP and DEA to evaluate and select nonhomogeneous suppliers, which do not give common outputs for evaluation. AHP was deployed to identify the relative weight of each supplier that had missing value. Ha and Krishnan (2008) attempted to evaluate suppliers performance using multiple methods (Integration of AHP, DEA, and Artificial Neural Network). AHP was used to evaluate the performance of suppliers and then the performance efficiency of each supplier was determined by using a combination of DEA and Artificial Neural Network (ANN). Wu (2009) proposed a multiple methodology using Neural Networks (NNs), Decision Tree (DT) and DEA to measure each supplier efficiency. Toloo and Nalchigar (2011) developed a new integrated data analysis (DEA) to evaluate efficiency of suppliers in presence of both cardinal and ordinal data and classifying them by considering multiple criteria integer linear programming. Ferreira and Borenstein (2012) proposed a novel method based on the integration of influence diagram and fuzzy logic to rank and evaluate suppliers.

\subsection{DEA models}

Assessing performance is very important for a decision maker unit (DMU) to realize its debilities so that following improvements can be made. Data envelopment analysis (DEA) introduced by Charnes et al. (1978) is a mathematical programming approach for measuring the relative efficiency of a set of DMUs which uses multiple inputs and outputs. Traditional approaches to efficiency have defined an efficiency score of a DMU by dividing weighted sum of outputs to weighted sum of inputs, while weights need to be allocated. To shun the difficulty in allocating these weights among various DMUs, a DEA model calculate weights that give the highest possible relative efficiency score to a DMU while keeping the efficiency scores of all DMUs less than or equal to 1 under the same set of weights. Suppose there are $n$ DMUs, each DMU with $m$ input indicators and $s$ output indicators. The CCR input oriented (CCR-I) model is given as follows to evaluate the efficiency of DMUo (DMU under consideration).

$\min \sum_{\mathrm{i}=1}^{\mathrm{m}} \mathrm{v}_{\mathrm{i}} \mathrm{x}_{\mathrm{r} 0}$

subject to

$\sum_{\mathrm{i}=1}^{\mathrm{m}} \mathrm{v}_{\mathrm{i}} \mathrm{x}_{\mathrm{ij}}-\sum_{\mathrm{r}=1}^{\mathrm{s}} \mathrm{u}_{\mathrm{r}} \mathrm{y}_{\mathrm{rj}} \geq 0$

$$
\begin{aligned}
& \mathrm{j}=1,2, \ldots, \mathrm{n} \\
& \mathrm{r}=1,2, \ldots, \mathrm{s} \\
& \mathrm{i}=1,2, \ldots, \mathrm{m}
\end{aligned}
$$$$
\sum_{\mathrm{r}=1}^{\mathrm{s}} \mathrm{u}_{\mathrm{r}} \mathrm{y}_{\mathrm{r} 0}=1
$$$$
\mathrm{u}_{\mathrm{r}} \geq \varepsilon
$$$$
\mathrm{v}_{\mathrm{i}} \geq \varepsilon
$$

where $\mathrm{x}_{\mathrm{ij}}$ and $\mathrm{y}_{\mathrm{rj}}$ (all nonnegative) are the inputs and outputs of the DMUj, $\mathrm{v}_{\mathrm{i}}$ and ur are the input and output weights. $\mathrm{x}_{\mathrm{r} 0}$ and $\mathrm{y}_{\mathrm{r} 0}$ are the inputs and outputs of DMUo and $\varepsilon$ is a value for forestalling weights to be equal to zero. To find the relative efficiency of all DMUs this model must be run $n$ times, once for each unit and those DMUo are efficient that their objective function results in unit 1 otherwise are inefficient. The dual model of this problem can be given as follows:

$\min \quad \mathrm{E}$

subject to

$\sum_{\mathrm{j}=1}^{\mathrm{n}} \mathrm{x}_{\mathrm{ij}} \lambda_{\mathrm{j}}-\mathrm{x}_{\mathrm{i} 0} \mathrm{E} \leq 0$

$\mathrm{i}=1,2, \ldots, \mathrm{m}$

$\sum_{\mathrm{j}=1}^{\mathrm{n}} \mathrm{y}_{\mathrm{rj}} \lambda_{\mathrm{j}}-\mathrm{y}_{\mathrm{r} 0} \geq 0$

$\mathrm{r}=1,2, \ldots, \mathrm{s}$

$\lambda_{j} \geq 0$, E free,

$\mathrm{j}=1,2, \ldots, \mathrm{n}$ 
The dual model has fewer constraints than the first one and so it can be solved easier. Similar to the first model there is a reasonable explanation behind the dual model and the optimal objective function value is 1 .

\section{Proposed DEA-GAHP model}

The motivation for developing GAHP model in supplier selection problem using DEA mainly stem from the common problem in estimating the efficiency of various decision making units (DMUs). DEA allows each DMU to specify its own weights to obtain its maximum efficiency score, which may result in a relatively high number of efficient DMUs and avoid DEA to appear as a robust approach in determining the most efficient unit (Doyle \& Green, 1994). In order to prevent unrealistic distribution of weights and to overcome the weak incriminating power of data envelopment analysis, many theories have been proposed to control the allowed flexibility and variation of weights in original DEA by imposing some extra weight restrictions on in DEA model. Although these theories usually improve the value judgments made by DEA through changing some restrictions in the model but they also reduce objectivity of data envelopment analysis. The proposed model does not just rank the efficient units (units with efficiency one) based on their performance, but it calculates the efficiency of all units by using common weights obtained from GAHP technique. The suggested method is described as the following steps:

\section{Step 1:}

First of all we are going to evaluate the efficiency and weights of all DMUs by the CCR input oriented model. In the next steps we will use GAHP to find a common weight for all DMUs.

$W_{j}=\left(v_{1 j}, v_{2 j}, \ldots, v_{i j}, u_{1 j}, u_{2 j}, \ldots, u_{r j}, \gamma_{j}\right)^{T} ; i=1,2, \ldots, m ; r=1,2, \ldots, s ; j=1,2, \ldots, n ;$

\section{Step 2:}

In this step, we form the pair wise comparison matrixes for weight vectors of each unit. The pair wise comparison matrixes have to be made for all of the DMUs. For instance the matrix for $\mathrm{DMU}_{\mathrm{J}}$ is as bellow:

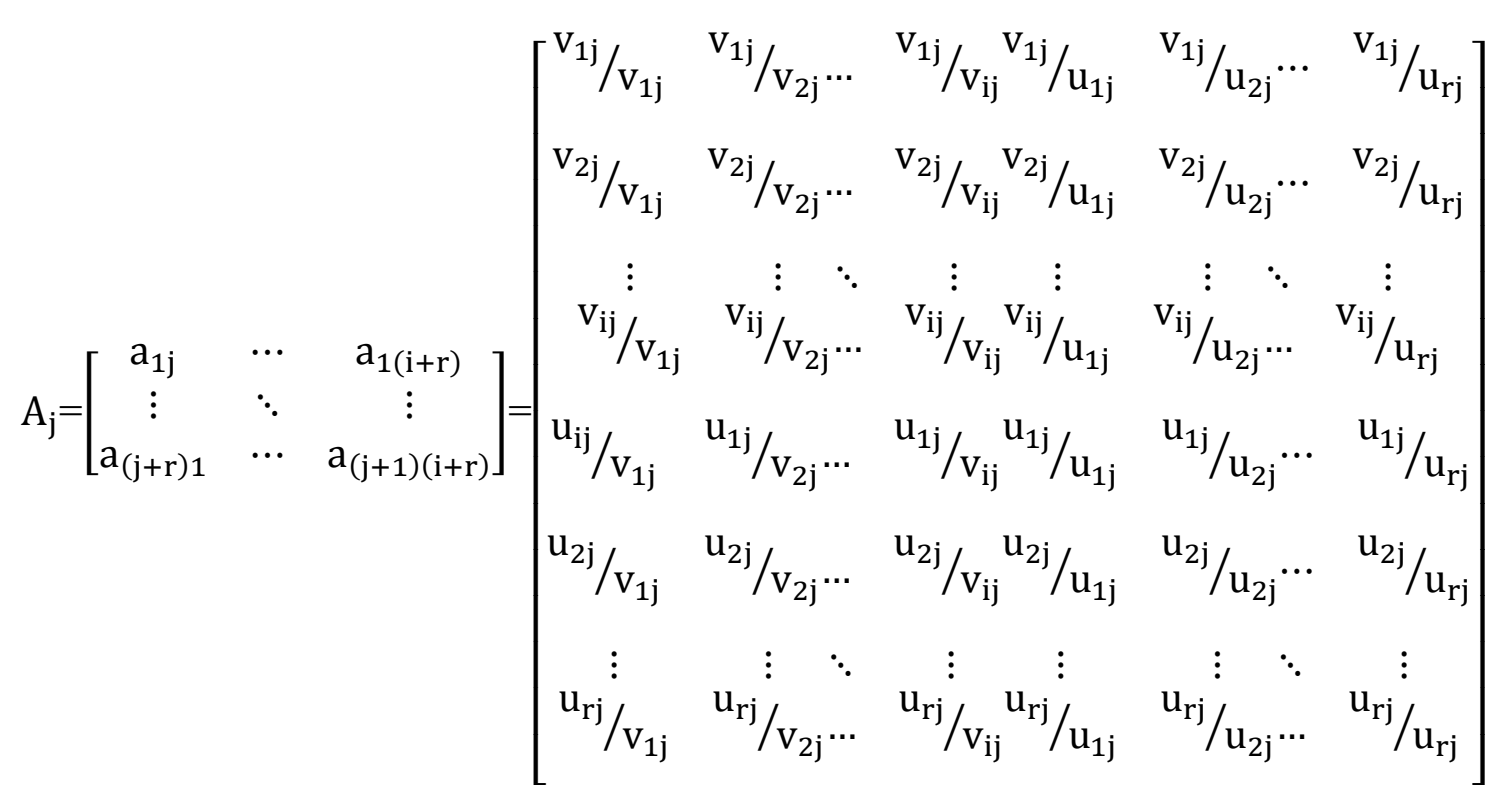

$j=1,2, \ldots, n$ 
The $\gamma_{\mathrm{j}}$ parameter will be calculated separately and do not take part in pair wise comparison matrix. Now we have $n$ comparison matrixes (pay off matrix) which have to be combined in to one matrix, using GAHP method. But before performing this, we have to ensure consistency of these matrixes. All the matrixes are consistent, because if we normalize them by the following relation, the rows of each matrix will be similar which means the consistency of each matrix.

$A_{m \times n}=\left(r_{i j}\right)_{m \times n} \rightarrow N_{m \times n}=\left(n_{i j}\right)_{m \times n} ; r_{i j}=\frac{r_{i j}}{\sum_{i=1}^{m} r_{i j}} j=1,2, \ldots, n ; \quad 0 \leq n_{i j} \leq 1$

\section{Step 3:}

In this step, we are going to combine matrixes obtained in previous stage.

$\left.W^{\prime}=\left(W_{(i+r)(i+r)}^{\prime}\right)_{(m+s)(m+s)}=\left(\prod_{j=1}^{n} a_{(i+r)(i+r) j}\right)\right)^{\frac{1}{n}}$

$\mathrm{W}^{\prime}$ is a combination of all matrixes which now have to be normalized in order to get the final weight vector $(\mathrm{W})$. The normalization procedure has described in step 2.

\section{Step4:}

Based on AHP concept the average of weights vector for all criteria has to be calculated in this step.

$\overline{\mathrm{W}}_{(\mathrm{i}+\mathrm{j})}=\frac{\sum_{\mathrm{r}=1}^{\mathrm{s}} \mathrm{W}_{(\mathrm{i}+\mathrm{r})(\mathrm{i}+\mathrm{r})}}{\mathrm{m}+\mathrm{s}} ; \mathrm{i}=1,2, \ldots, \mathrm{m} ; \mathrm{j}=1,2, \ldots, \mathrm{n}$

$\overline{\mathrm{W}}=\left(\overline{\mathrm{W}}_{1}, \overline{\mathrm{W}}_{2}, \ldots, \overline{\mathrm{W}}_{(\mathrm{i}=\mathrm{r})}\right)^{\mathrm{T}}=\left(\mathrm{v}_{1}^{*}, \mathrm{v}_{2}^{*}, \ldots, \mathrm{v}_{\mathrm{i}}^{*}, \mathrm{u}_{1}^{*}, \mathrm{u}_{2}^{*}, \ldots, \mathrm{u}_{\mathrm{r}}^{*}\right)^{\mathrm{T}} ; \mathrm{i}=1,2, \ldots, \mathrm{m} ; \mathrm{r}=1,2, \ldots, \mathrm{s}$

$\bar{W}$ is the common weights vector obtained from GAHP. Now we need common $\gamma_{j}$ for evaluating the efficiency. The calculation of this parameter is explained in the next step.

\section{Step 5:}

$\sum_{\mathrm{r}=1}^{\mathrm{s}} \mathrm{u}_{\mathrm{r}}^{*} \gamma_{\mathrm{rj}}-\sum_{\mathrm{i}=1}^{\mathrm{m}} \mathrm{v}_{\mathrm{i}}^{*} \mathrm{x}_{\mathrm{ij}}+\gamma^{*} \leq 0 ; \quad$ for all DMUs

$\sum_{\mathrm{r}=1}^{\mathrm{s}} \mathrm{u}_{\mathrm{r}}^{*} \gamma_{\mathrm{rj}}-\sum_{\mathrm{i}=1}^{\mathrm{m}} \mathrm{v}_{\mathrm{i}}^{*} \mathrm{x}_{\mathrm{ij}}+\gamma^{*}=0 \quad$ for at least one DMU

So we have:

$\gamma^{*}=\min \left\{v_{i}^{*} x_{i j}-u_{r}^{*} y_{r j}\right\} ; i=1,2, \ldots, m ; j=1,2, \ldots, n ; r=1,2, \ldots, s$

\section{Step 6:}

Now we have the grouped common weight $\left(\mathrm{v}^{*}, \mathrm{u}^{*}, \gamma^{*}\right)$ and it is possible to calculate the efficiency of each DMU as below:

$\operatorname{Eff}(D M U)=\frac{\sum_{\mathrm{i}=1}^{\mathrm{m}} \mathrm{v}_{\mathrm{i}}^{*} \mathrm{x}_{\mathrm{ii}}-\gamma^{*}}{\sum_{\mathrm{r}=1}^{\mathrm{s}} \mathrm{u}_{\mathrm{i}}^{*} \mathrm{y}_{\mathrm{rj}}} ; \mathrm{j}=1,2, \ldots, \mathrm{n}$

\subsection{Illustrative example}

Suppose a company wants to evaluate 12 suppliers. Also, consider there are two inputs, distance and cost reduction (CR) and 5 outputs, delivery, cost, supplied varieties, cost reduction performance (CRP) and other. Weight vectors and efficiency of all suppliers are calculated using BCC output oriented model and are shown in Table 1. 


\section{Table 1}

Inputs and outputs for 12 suppliers

\begin{tabular}{lccccccc}
\hline \multirow{2}{*}{ Suppliers } & \multicolumn{3}{c}{ Input } & \multicolumn{5}{c}{ Outputs } \\
\cline { 2 - 8 } & Distance & Cost Reduction & Delivery & Cost & Supplied Varieties & (CRP) & Other \\
\hline 1 & 215 & 23.5 & 62.5 & 320 & 6 & 9.5 & 10.5 \\
2 & 105 & 12.5 & 13.5 & 129 & 4.5 & 9 & 12 \\
3 & 152.5 & 51 & 37.5 & 187.5 & 4.5 & 4.5 & 15.5 \\
4 & 112.5 & 22 & 12.5 & 139 & 2.5 & 13.5 & 5.5 \\
5 & 60 & 7 & 5.5 & 81.5 & 8.5 & 2.25 & 9 \\
6 & 50 & 10 & 23 & 81 & 7 & 3 & 7.5 \\
7 & 84.5 & 13 & 19 & 127 & 3 & 3 & 15 \\
8 & 27 & 8 & 29 & 67.5 & 5.5 & 4.5 & 11 \\
9 & 172 & 21.5 & 17.5 & 217.5 & 4 & 3.5 & 10 \\
10 & 212.5 & 24.5 & 31.5 & 280 & 6.5 & 14 & 10.5 \\
11 & 114 & 6 & 23 & 266 & 7.5 & 10 & 11 \\
12 & 45.5 & 5 & 28.5 & 81.5 & 7.5 & 11 \\
\hline
\end{tabular}

The input and output weights of the supplier selection problem are calculated and indicated in Table 2.

\section{Table 2}

Input and output weights

\begin{tabular}{lccccccccc}
\hline Supplier & $v_{1}$ & $v_{2}$ & $u_{1}$ & $u_{2}$ & $u_{3}$ & $u_{4}$ & $u_{5}$ & $\gamma$ & Efficiency \\
\hline 1 & 0.16676 & 0.00001 & 0.00001 & 0.00312 & 0.00001 & 0.00001 & 0.00001 & -0.64122 & 1 \\
2 & 0.00308 & 0.00001 & 0.00001 & 0.00001 & 0.03549 & 0.00001 & 0.06989 & -0.89610 & 0.8199 \\
3 & 0.00001 & 0.00521 & 0.02661 & 0.00001 & 0.00001 & 0.00001 & 0.00001 & -0.73300 & 0.99999 \\
4 & 0.00434 & 0.00001 & 0.00001 & 0.00001 & 0.00001 & 0.07396 & 0.00001 & -0.54310 & 0.9689 \\
5 & 0.00001 & 0.00001 & 0.00001 & 0.00281 & 0.90725 & 0.00001 & 0.00001 & -0.62595 & 1 \\
6 & 0.00623 & 0.00206 & 0.00001 & 0.00074 & 0.13422 & 0.00001 & 0.00001 & -1.05692 & 0.9276 \\
7 & 0.00534 & 0.00001 & 0.00001 & 0.00001 & 0.00001 & 0.01409 & 0.05905 & -0.54860 & 1 \\
8 & 0.00235 & 0.00001 & 0.03445 & 0.00001 & 0.00001 & 0.00001 & 0.00001 & -0.93649 & 1 \\
9 & 0.00001 & 0.00001 & 0.00001 & 0.00284 & 0.00001 & 0.00001 & 0.03810 & -1.30835 & 0.7631 \\
10 & 0.00063 & 0.00001 & 0.00001 & 0.00262 & 0.00001 & 0.01719 & 0.00001 & -0.86542 & 1 \\
11 & 0.00857 & 0.00001 & 0.00001 & 0.00376 & 0.00001 & 0.00001 & 0.00001 & -0.02252 & 1 \\
12 & 0.00178 & 0.00001 & 0.02885 & 0.00001 & 0.02356 & 0.00001 & 0.00001 & -0.91895 & 1 \\
\hline
\end{tabular}

Now we have to form pair wise comparison matrixes and then combine them using step 3 formula. In order to shorten our example we skip writing all comparison matrixes and just calculate the normalized combined matrix obtained from step 2.

$\mathrm{W}=\left[\begin{array}{ccccccc}0.875435 & 0.926825 & 0.858041 & 0.889560 & 0.895308 & 0.799601 & 0.887414 \\ 0.008624 & 0.002333 & 0.000416 & 0.008241 & 0.001622 & 0.002012 & 0.001608 \\ 0.009326 & 0.013747 & 0.009159 & 0.009493 & 0.009284 & 0.008532 & 0.035310 \\ 0.032924 & 0.097143 & 0.032334 & 0.033530 & 0.033740 & 0.030133 & 0.015103 \\ 0.039594 & 0.023159 & 0.0411391 & 0.042430 & 0.043192 & 0.143728 & 0.042810 \\ 0.024895 & 0.006774 & 0.008663 & 0.792900 & 0.007981 & 0.008073 & 0.008959 \\ 0.006570 & 0.012763 & 0.008503 & 0.008815 & 0.008872 & 0.007921 & 0.0087945\end{array}\right]$

In step 4 the average of weights vector has to be calculated:

$$
\overline{\mathrm{W}}=\left(\mathrm{v}_{1}^{*}, \mathrm{v}_{2}^{*}, \ldots, \mathrm{v}_{\mathrm{i}}^{*}, \mathrm{u}_{1}^{*}, \mathrm{u}_{2}^{*}, \ldots, \mathrm{u}_{\mathrm{r}}^{*}\right)^{\mathrm{T}}=(0.8938,0.0035,0.0135,0.0274,0.0528,0.0047,0.0089)
$$

Now we have to calculate $\gamma^{*}$ to complete the parameters of weights vector (step5):

$\gamma^{*}=\min \left\{\mathrm{v}_{\mathrm{i}}^{*} \mathrm{x}_{\mathrm{ij}}-\mathrm{u}_{\mathrm{r}}^{*} \mathrm{y}_{\mathrm{rj}}\right\}=21.516519$ 
In final step, we can find the efficiency of all DMUs using common weights vector (Table 3).

Table 3

Efficiency and ranking of the suppliers in DEA-GAHP method

\begin{tabular}{|c|c|c|c|c|c|c|c|c|c|c|c|c|}
\hline Supplier & $\mathrm{P}_{1}$ & $P_{2}$ & $\mathrm{P}_{3}$ & $\mathrm{P}_{4}$ & $\mathrm{P}_{5}$ & $\mathrm{P}_{6}$ & $\mathrm{P}_{7}$ & $\mathrm{P}_{8}$ & $\mathrm{P}_{9}$ & $\mathrm{P}_{10}$ & $\mathrm{P}_{11}$ & $P_{12}$ \\
\hline Efficiency & 190 & 17.7 & 19 & 18.7 & 11.3 & 7.8 & 13.3 & 1 & 20.2 & 19.9 & 9.8 & 5.9 \\
\hline Rank & 12 & 7 & 9 & 8 & 5 & 3 & 6 & 1 & 11 & 10 & 4 & 2 \\
\hline
\end{tabular}

\section{Conclusion}

This paper highlighted a combination of DEA and GAHP methods to evaluate and rank existing suppliers based on their efficiency. The importance of supplier selection and the relevant methodologies for evaluating suppliers have introduced in this paper and observed that there is an inconsistency in estimating efficiency of various decision maker units (DMUs) in original DEA. Many approaches have been developed to solve this problem but they reduced the accuracy of DEA in some cases. But the proposed GAHP method puts the results of a CCR output oriented model in a process to combine suppliers weights and achieve grouped common weight $\left(\mathrm{v}^{*}, \mathrm{u}^{*}, \gamma^{*}\right)$ in order to find the most efficient DMU.

\section{References}

Banker, R.D., \& Khosla, I. S. (1995). Economics of operations management: A research perspective. Journal of Operations Management, (12), 423-425.

Bayazit, O. (2006). Use of analytic network process in vendor selection decisions. Benchmarking: An International Journal, 13 (5), 566-579.

Braglia, M., \& Petroni, A. (2000). A quality assurance-oriented methodology for handling trade-offs in supplier selection. International Journal of Physical Distribution and Logistics Management, 30(2), 96111.

Bhutta, K.S., \& Huq, F. (2002). Supplier selection problem: a comparison of the total cost of ownership and analytic hierarchy process approaches. Supply Chain Management: An International Journal, 7(3), 126135.

Chan, F.T.S., \& Chan, H.K. (2004). Development of the supplier selection model - A case study in the advanced technology industry. Proceedings of the Institution of Mechanical Engineers Part B - Journal of Engineering Manufacture, 218(12), 1807-1824.

Charnes, A., Cooper, W. W., \& Rhodes, E. (1978). Measuring the efficiency of decision-making units. European Journal of Operational Research, 2, 429-444.

Chen, C.T., Lin, C.T., \& Huang, S.F. (2006). A fuzzy approach for supplier evaluation and selection in supply chain management. International Journal of Production Economics, 102 (2), 289-301.

Ferreira, L, \& Borenstein, D. (2012). A fuzzy-Bayesian model for supplier selection. Expert Systems with Applications 39(9), 7834-7844.

Florez-Lopez, R. (2007). Strategic supplier selection in the added-value perspective: A CI approach. Information Sciences, 177 (5), 1169-1179.

Forker, L.B., Mendez, D. (2001). An analytical method for benchmarking best peer suppliers. International Journal of Operations and Production Management, 21(1-2), 195-209.

Garfamy, R.M. (2006). A data envelopment analysis approach based on total cost of ownership for supplier selection. Journal of Enterprise Information Management, 19 (6), 662-678.

Gencer, C., \& Gürpinar, D. (2007). Analytic network process in supplier selection: A case study in an electronic firm. Applied Mathematical Modeling, 31(11), 2475-2486.

Ghodsypour, S.H., \& O'Brien, C. (2001). The total cost of logistics in supplier selection, under conditions of multiple sourcing, multiple criteria and capacity constraint. International Journal of Production Economics, 73(1), 15-27.

Ha, S.H., \& Krishnan, R. (2008). A hybrid approach to supplier selection for the maintenance of a competitive supply chain. Expert Systems with Applications, 34 (2), 1303-1311.

Heizer, J., \& Render, B. (2006). Operations Management. $8^{\text {th }}$ ed., Prentice-Hall, Englewood Cliffs, NJ. 
Hong, G.H., Park, S.C., Jang, D.S., \& Rho, H.M. (2005). An effective supplier selection method for constructing a competitive supply-relationship. Expert Systems with Applications, 28(4), 629-639.

Hou, J., \& Su, D. (2007). EJB-MVC oriented supplier selection system for mass customization. Journal of Manufacturing Technology Management, 18(1), 54-71.

Karpak, B., Kumcu, E., \& Kasuganti, R.R. (2001). Purchasing materials in the supply chain: Managing a multi-objective task. European Journal of Purchasing and Supply Management, 7(3), 209-216.

Leenders, M., Johnson, P.F., Flynn, A., \& Fearon, H.E. (2006). Purchasing Supply Management. $13^{\text {th }}$ ed., McGraw-Hill, New York, NY.

Liu, F.H.F., \& Hai, H.L. (2005). The voting analytic hierarchy process method for selecting supplier. International Journal of Production Economics, 97(3), 308-317.

Monczka, R.M., Trent, R., \& Handfield, R. (2002). Purchasing and Supply Chain Management, $2^{\text {nd }}$ ed., SouthWestern/Thomson Learning, Cincinnati, OH.

Narasimhan, R., Talluri, S., \& Mendez, D. (2001). Supplier evaluation and rationalization via data envelopment analysis: An empirical examination. Journal of Supply Chain Management, 37(3), 28-37.

Narasimhan, R., Talluri, S., \& Mahapatra, S.K. (2006). Multiproduct, multicriteria model for supplier selection with product life-cycle considerations. Decision Sciences, 37 (4), 577-603.

$\mathrm{Ng}$, W. L. (2008). An efficient and simple model for multiple criteria supplier selection problem. European Journal of Operational Research, 186, 1059-1067.

Ramanathan, R. (2007). Supplier selection problem: Integrating DEA with the approaches of total cost of ownership and AHP. Supply Chain Management: An International Journal, 12 (4), 258-261.

Ross, A., Buffa, F.P., Dröge, C., \& Carrington, D. (2006). Supplier evaluation in a dyadic relationship: An action research approach. Journal of Business Logistics, 27 (2),75-102.

Saen, R.F. (2007a). Suppliers selection in the presence of both cardinal and ordinal data. European Journal of Operational Research, 183 (2), 741-747.

Saen R.F. (2007b). A new mathematical approach for supplier selection: Accounting for non-homogeneity is important. Applied Mathematics and Computation, 185(1), 84-95.

Sarkar, A., \& Mohapatra, P.K.J. (2006). Evaluation of supplier capability and performance: A method for supply base reduction. Journal of Purchasing and Supply Management, 12 (3), 148-163.

Seydel, J. (2005). Supporting the paradigm shift in vendor selection: Multicriteria methods for sole sourcing. Managerial Finance, 31 (3), 49-66.

Seydel, J. (2006). Data envelopment analysis for decision support. Industrial Management and Data Systems, $106(1), 81-95$.

Talluri, S. (2002). A buyer-seller game model for selection and negotiation of purchasing bids. European Journal of Operational Research, 143 (1), 171-180.

Talluri, S., \& Baker, R.C. (2002). A multi-phase mathematical programming approach for effective supply chain design. European Journal of Operational Research 141 (3), 544-558.

Talluri, S., \& Narasimhan, R. (2003). Vendor evaluation with performance variability: A max-min approach. European Journal of Operational Research, 146 (3), 543-552.

Talluri, S., \& Narasimhan, R. (2005). A note on "a methodology for supply base optimization". IEEE Transactions on Engineering Management, 52 (1), 130-139.

Talluri, S., \& Narasimhan, R. (2004). A methodology for strategic sourcing. European Journal of Operational Research, 154(1), 236-250.

Toloo, M., \& Nalchigar, M. (2011). A new DEA method for supplier selection in presence of both cardinal and ordinal data. Expert Systems with Applications, 38, 14726-14731.

Ho, W., Xu, X., \& Dey, P.K. (2009). Multi-criteria decision making approaches for supplier evaluation and selection: A literature review. European Journal of Operational Research, 202, 16-24.

Wadhwa, V., \& Ravindran, A.R. (2007). Vendor selection in outsourcing. Computers \& Operations Research, 34(12), 3725-3737.

Weber, C.A., Current, J.R., \& Desai, A. (2000). An optimization approach to determining the number of vendors to employ. Supply Chain Management: An International Journal, 5 (2), 90-98.

Wu, T., Shunk, D., Blackhurst, J., \& Appalla, R. (2007). AIDEA: A methodology for supplier evaluation and selection in a supplier-based manufacturing environment. International Journal of Manufacturing Technology and Management, 11(2), 174-192.

Wu, D. (2009). Supplier selection: A hybrid model using DEA, decision tree and neural network. Expert Systems with Applications, 36(5), 9105-9112. 